lights tell us (a) how a vessel is heading and (b) what type of vessel she is. A single white light would tell us neither of these two things. How is a boat in a fleet of small boats expected to manœuvre in relation to the others without any indication of whether any of the single white lights seen ahead is coming or going ?

Following Mr. Lindsay's proposals, it might be a relief for a yacht to be given right of way over all larger ships, but the resulting chaos from one's own kind would be an uncomfortable alternative.

\title{
Signals for Vessels in Sight of One Another
}

\author{
D. A. Rodger \\ (Second Officer, P. \& O.)
}

I HAve been following the articles on this subject in the Journal 1 with some interest and hope that the personal views of one comparatively junior officer may be of some interest.

It is implicit in all these articles that, except in the close-quarter situation which the Rules are surely designed to prevent, the sound signals are unsatisfactory. What is not stated in so many words is that, international conferences notwithstanding, Rule 28 (a) is more observed in the breach than otherwise. I cannot of course be sure, but I suspect that this has been so since electric navigation lights superseded oil in general use, thus increasing the recognition range and allowing avoiding action to be taken at greater distances. There is also the natural human, if not legally commendable, desire to let sleeping captains lie.

I am sure that, of the suggested signals, the simple flashing light of the appropriate colour is by far the best. The directional arrow concept seems an oversubtle solution to the problem. As an officer on watch, what I want is a flashing light which I switch on to indicate that I am starting a turn, and which I switch off, or preferably which switches itself off, when the turn is complete. The other ship would see by the flashing that I was turning, or just about to turn, and when the flashing stopped he could tell by my aspect how I was heading. If thought desirable, white flashes could be used to indicate 'my engines are going full speed astern'. I should want these signals to be visible clearly by day, yet not to be too bright by night, so some form of dimming arrangement would have to be incorporated.

The variations of short and long flashes put forward by Lindsay would seem to be an unnecessary elaboration, and the warning lag of two minutes suggested by Commander Parmiter is vulnerable when speeds in excess of 20 knots give an advance of more than $\frac{3}{4}$ mile in that time. Technically it should not be difficult 
to produce. All that is required is a single unit incorporating a white, a red and a green all round light-the white light could double as a Morse light. This unit should be placed where it could best be seen, and direct light screened from the bridge. A control box should be fitted in the wheelhouse, and at any other steering positions. The only switches required on this box would be an on-off switch for each colour, and a bright-dim switch to control the intensity. An automatic off-switch to operate when opposite helm is applied would be a desirable, but not an essential, refinement; as would warning lights.

I agree with Lindsay on the usefulness of rapid flashes on a directional light as an alternative to the short and rapid blasts on the whistle authorized by Rule 28 (b), and as he states, this is being used at sea today.

Finally, on an indirectly related topic, it would be interesting to know whether, with the introduction of bridge control of main engines, ships do now slacken speed in accordance with Rule 23 as an alternative to altering course.

\title{
REFEREN CES
}

1 Wepster, A. (1966). Visual direction indication for ships. This Journal, 19, 265.

2 Parmiter, G. V. (1966). Visual indication of direction for ships. This Journal, 19, 394.

3 Potts, J. J. (1967). Visual direction indication for ships. This Journal, 20, 105 .

4 Lindsay, D. J. (1967). Improvement of navigation lights and signals. This Journal, 20, 249.

\section{The Effect of Surveying Techniques on Underkeel Clearance}

\author{
Lt-Cmdr. C. G. McQ. Weeks, R.N.(Ret.)
}

1. Introduction. In the paper which he read on 19 April 1967, Captain Dickson 1 described in some detail the investigations which have been carried out to determine the underkeel clearance which should be allowed in any given circumstance. These investigations have concentrated on the vertical movement of a tanker under different conditions, particularly in determining squat and the effect of wave motion. However, another factor in the underkeel clearance equation is the charted depth and this also is affected by ship movement, in this case the movement of the surveying vessel which obtained the soundings. In the following note the probable effect of this movement is discussed and suggestions made by which the effect might be reduced.

2. Sounding swell factor. Fig. I illustrates the kind of echo trace that might be obtained by a surveying motor boat over a perfectly flat bottom in a 2- or 3-ft. sea. The apparent variation in depth is caused partly by rolling and partly by vertical movement of the boat, but in either case the mean depth will be the true value, and this is the value normally inked in. Where a shoal is concerned, however, the risk cannot be ignored that the shallowest sounding was caused not by the sea but by the peak of the shoal, and in this case the least depth indicated is invariably selected. 